\title{
Semi-desert fruit farms harbor more native flora than Mediterranean climate farms in central Chile
}

\author{
Alejandra E. Muñoz ${ }^{1}$ (D) Paul Amouroux ${ }^{1 *}$ (D), Nicolás Arcos $^{1}$ (1) and Cristián Bonacic ${ }^{1}$ (D)
}

Received: March 16, 2020

Accepted: October 20, 2020

\begin{abstract}
Understanding the factors that affect native plant communities is essential to protect floristic diversity, particularly in Mediterranean agroecosystems. The Chilean Mediterranean-climate area supports high species richness and levels of endemism, and harbors the main fruit production. We investigated whether the richness of native and non-native flora differs between two Mediterranean climate areas of Chile with contrasting rainfall levels in both cultivated and uncultivated habitats. Thirteen fruit farms under conventional management were prospected in the spring of 2015 and of 2016 by sampling in square meter quadrants $(\mathrm{N}=3,630)$. A total of 191 vascular plants were found, $48.2 \%$ of them native, $50.3 \%$ non-native and $1.6 \%$ not identified. Species richness was low in both areas and habitat types. However, there were more native species in uncultivated habitats in the Mediterranean-to-desert transition area than in the mesic Mediterranean area, and the contrary was observed for non-native species. Our results suggest that wetter Mediterranean climate areas are more prone to the establishment of non-native plant species.
\end{abstract}

Keywords: agroecosystems, exotic species, native flora, non-crop habitats, plant species richness

\section{Introduction}

Agriculture is closely related to plant conservation worldwide. It is also one of the main factors negatively affecting biodiversity, given the conversion/destruction of natural habitat for agriculture, causing toxification from pesticides and fertilizers and generation of greenhouse gases from fossil fuel use (Chappell \& LaValle 2011). Plant diversity has declined significantly on agricultural land in Europe (Waldhardt et al. 2003) and North America (Boutin \& Jobin 1998) in recent decades. The intensification of agriculture is considered one of the main drivers of invasive plant species because of the intense levels of propagule pressure and disturbance (Chytrý et al. 2008; Gassó et al.
2012; Clotet et al. 2016). Agricultural fields can function as sources of weeds that invade neighboring habitats and reduce native plant diversity (Boutin et al. 2008).

A better understanding of the specific factors that affect native plant communities is increasingly important, considering the growing loss of biodiversity globally (Carboni et al. 2010). The number, cover and composition of plant species varies among agroecosystems according to farm practice, habitat type and geographic location (Boutin \& Jobin 1998; Armengot et al. 2012). In areas within or adjacent to intensively farmed plots, herbaceous weeds are expected to predominate in species richness and abundance, given their capacity to tolerate and adapt to agricultural practices (Boutin \& Jobin 1998). It is known that the establishment, dispersal and distribution of non-native

1 Facultad de Agronomía e Ingeniería Forestal, Pontificia Universidad Católica de Chile, 7820436, Macul, Santiago de Chile, Chile

* Corresponding author: pamourou@yahoo.fr 
species respond to biological factors such as competition, but also to environmental factors like precipitation and soil nutrients and to disturbances of anthropic origin (Carboni et al. 2010; Chen et al. 2016). Variation in precipitation appears to be an important predictor of plant invasion, but more research is needed to determine if precipitation favors plant invasion (Bradley et al. 2010; Chen et al. 2016). The successful establishment of non-native species in an ecosystem does not necessarily imply the reduction of richness in native species, when biotic factors are not predominating, and species richness may be promoted by environmental factors that also promote invasion (Alpert et al. 2000; Gilbert \& Lechowicz 2005). But negative correlations between native and non-native species are expected when biotic factors like competition are important in the naturalization process (Martín-Forés et al. 2015).

Mediterranean climate areas hold a particularly rich and endemic flora, and therefore are important from the perspective of conservation. Areas with Mediterranean climates represent less than $5 \%$ of the Earth's land surface, while hosting almost $20 \%$ of vascular plants. However, these ecosystems have dense human populations and long-term development of agriculture and animal husbandry (Cowling et al. 1996). Agriculture, urban areas and population density are considered threats to biodiversity in the Mediterranean biome (Underwood et al. 2009). However, the Mediterranean basin has suffered anthropogenic landscape alterations for thousands of years, while other Mediterranean climate areas such as central Chile have suffered intensive human alterations threatening their biodiversity for a much shorter time (Martín-Forés et al. 2015).

High levels of species richness and endemism as well as threats to conservation of the biota in Chile are concentrated in the Mediterranean climate area, which is recognized as one of the world's biodiversity hotspots (Myers et al. 2000). A dramatic widespread substitution of the vegetation of Central Chile by non-native plantations and agriculture has occurred during the last decades (Moreira-Muñoz 2011). Extensive goat grazing has strongly affected the vegetation in the northern part of Mediterranean climate area (Pozo et al. 2006). Chilean Mediterranean climate flora has a high level of species richness relative to surface area (ca. 2,500 species in $155,000 \mathrm{~km}^{2}$ ) and diversified plant genera; nearly $50 \%$ of the species are endemic to the area (Marticorena 1990). The vegetation is also diversified, with plant communities ranging from semi-desert to forest vegetation (Arroyo 1999).

Less than five percent of the regional surface of the Mediterranean climate area is part of the national system of protected areas, and their plant communities are the least represented (Luebert \& Pliscoff 2006). Agriculture is also concentrated in the Mediterranean climate part of Chile, according to the most recent National Agricultural Census. Around $77 \%$ of fruit farms and $90 \%$ of vineyards are located in valleys between the Coquimbo $\left(29^{\circ} \mathrm{S}\right)$ and Bío-Bío Regions $\left(38.5^{\circ} \mathrm{S}\right)$, with a characteristically Mediterranean climate (INE
2007). Climate conditions in that wide latitudinal range differ from the xeric conditions in the desert-to-Mediterranean transition area in the north and the rainier conditions at more southern latitudes (Luebert \& Pliscoff 2006).

Consideration of agricultural lands for biodiversity conservation is recognized as a "land-sharing approach" in contraposition to a land-spare one (Phalan et al. 2011). And although not all farmlands are suitable for that purpose, some criteria like landscape structure can guide the choice towards one or the other (Baudron \& Giller 2014). Many fruit farms in Chile have large uncultivated areas (even larger than cultivated ones) under private ownership, which could contribute to biological conservation.

The aim of this study is to evaluate the potential contribution of fruit farms located in the Mediterranean climate of Chile to conservation of native vascular flora, and to what extent the plant community is dominated by non-native species. Specifically, we assessed the native and non-native plant species richness in fruit agroecosystems and their variation, within the farms (in cultivated versus uncultivated habitats), and between farms located in two different Mediterranean climate areas about $400 \mathrm{~km}$ apart in latitude. We assessed the interaction between native and non-native species richness in the areas and habitats. To highlight the importance of intra-farm habitats, we classified the species according to biogeographic origin, conservation status and whether they are considered weeds in Chile. We hypothesize that species richness of non-native species, mainly weeds, will be higher in cultivated habitats in both areas, while native species dominate uncultivated habitats. We also hypothesized that native species in uncultivated habitats vary between these two distant areas.

\section{Materials and methods}

\section{Study area}

Thirteen fruit farms were prospected. Four farms are located in valleys in the Coquimbo Region $\left(30.3^{\circ} \mathrm{S}\right)$, in the Mediterranean-to-desert transition area (MDT), while the other nine are in valleys in the $\mathrm{O}^{\prime} \mathrm{Higgins}$ Region $\left(34.3^{\circ} \mathrm{S}\right)$, in the mesic Mediterranean area (MM; Fig. 1). Annual rainfall in the valleys in the Coquimbo Region is around $85 \mathrm{~mm}$ (average between Vicuña and Ovalle stations over the last decade (Dirección General de Aguas 2017); while annual rainfall in the valleys in the O'Higgins Region is around $500 \mathrm{~mm}$ (526 $\mathrm{mm}$ on average in Coltauco over the last decade (Dirección General de Aguas 2017). The first soil component of the farms in the Coquimbo Region is eutric leptosols or petric calcisols, associated with eutric cambisols and eutric fluvisols, respectively. The first soil component of the farms in the O'Higgins Region is petric calcisols or chromic luvisols, associated with eutric fluvisols and calcic vertisols (FAO 1998; Batjes 2005). 

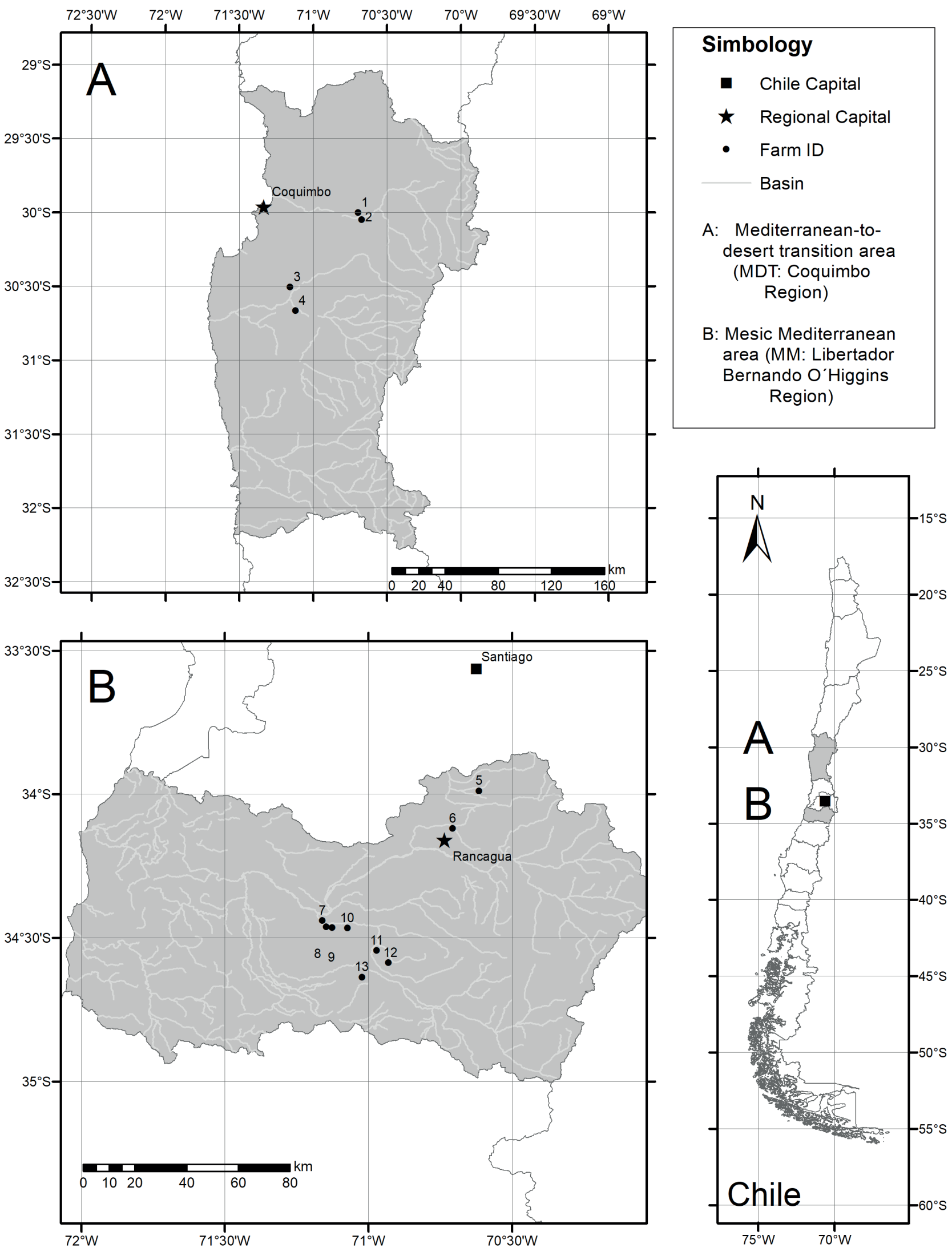

Figure 1. Location of farms in the Mediterranean-to-desert transition area (Coquimbo Region, $\mathbf{A}$ ) and the mesic Mediterranean area (Libertador Bernardo O’Higgins Region, B). Scales are: 1:30,000,000 for Chile; 1:3,500,000 for A; 1:1,800,000 for B. 
Farms cultivate mainly table grapes (10 of the 13 farms) and citrus fruit. The size of cultivated areas ranges between 15 and 223 ha (Median $=48$ ha), and total farm areas are between 17 and 985 ha (Median = 60 ha). The farms are under conventional management with the application of fertilizers and herbicides. The most commonly applied herbicides are Glyphosate and Flumioxazim (both broadspectrum); they are applied in late winter and spring.

\section{Data collection}

Two intra-farm habitats were distinguished: cultivated habitats (C) and uncultivated habitats (UC). Uncultivated habitats on farms (when available) feature semi-dense shrubland and some sclerophyllous forest only in the MM zone. Different plant formations were observed and distinguished by freely available satellite imagery (Google Earth (c). Fruit crops in $\mathrm{C}$ habitats and plant formations on adjacent UC habitats (there were a maximum of two vegetal formations per farm) were prospected using transects (see Fig. $S 1$ in supplementary material). Transects were used to assess species richness. Each transect was composed of ten quadrants (one square meter each) arranged in a line with a separation of $0.5 \mathrm{~m}$ between them. Species richness was determined based on the number of species per quadrant.

To obtain the minimum number of transect repetitions in $C$ and UC habitats, previous study based on data collected in the majority of farms showed that a minimum of seven transects per UC habitat and five transects per $C$ habitat were sufficient to cover the full degree of variability (Ramírez 2015). According to this result, seven transects were analyzed for each UC habitat, and 15 and 10 transects in the $C$ habitat of the MM and MDT areas, respectively.

All individuals identified to the species level were classified according to three criteria: biogeographic origin (native, non-native, endemic), conservation status following the national classification system (RCE; i.e., Critically Endangered (CR), Endangered (EN), Vulnerable (VU), Near Threatened (NT) and Least Concern (LC)), and whether the species is considered as a weed in Chilean agroecosystems (Matthei 1995). According to Matthei (1995), weeds are plants that compete with crops directly or are harmful to people and/or other animals. The nomenclature of plants follows the on-line "Catalog of the Vascular Plants of Southern Cone Flora" by the Darwinian Botany Institute (Instituto de Botánica Darwinion 2017) and the "Catalogue of the vascular plants of Chile" for common names (Rodriguez et al. 2018).

Vascular flora in farms was sampled over 21 days of fieldwork, in September 2015, in the MM area and in August 2016, in the MDT area. The difference of one month in the sampling dates between the two areas reflects the fact that the phenology of at least the same fruit crops is more advanced in the MDT area. Rainfall levels up to the sampling date were normal (i.e., between average and standard deviation of the previous ten years) in both sampling areas (Dirección General de Aguas 2017).

\section{Statistical analysis}

To assess the difference in plant species richness, we built generalized linear mixed models (GLMM) using plant species richness per quadrant as the response variable, habitats (uncultivated vs. cultivated) and areas (Mediterranean-todesert transition area vs. mesic Mediterranean area) as fixed effect terms, and fruit farms as the random effect term. Since richness was measured on individual quadrants within transects, the random effect was nested by transects. A topdown selection model was performed from the complete GLMM model with the Habitat-Area interaction, defined as follows:

\section{Richness $\sim$ Habitat + Area + Habitat:Area + (1 | Farm/Transect $)$}

The model selection was based on the Akaike information criterion (AIC) and model validation was based on the graphic representation of residuals (Zuur et al. 2009; Barbizan Sühs et al. 2018). We chose the Poisson error distribution (log link) for all models because it fitted the residuals better visually than the negative binomial distribution. The analyses were conducted for native and non-native plant species richness independently. All analyses were run with the software R 3.6.2 (R Development Core Team 2019) using the packages 'glmmADMB' (Skaug et al. 2016) for GLMMs, and 'gplots' (Warnes et al. 2020) for the graphic representation.

To evaluate the possible synergy or trade-off between native and non-native species, the correlation between species richness was analyzed in total and within each area. For that purpose, Pearson correlation coefficients were calculated using the packages 'stats' (R Development Core Team 2019), and 'ggplot2' (Wickham 2016) for the graphic representation.

\section{Results}

\section{Flora}

A total of 191 vascular plant species belonging to 62 families were found in the 3,630 quadrants on fruit farms (Tab. S1 in supplementary material). Forty-three species were present in both MDT and MM areas. The families with the largest numbers of species were Asteraceae (31 species), Poaceae (19) and Fabaceae (13). The majority of species were herbaceous plants (131), followed by shrubs (31) and trees (25). Four succulent species and one parasitic species were also found. Herbaceous plants were the most common in both C (86.3\% of all species) and UC (65.7\%) habitats. Eighty species $(41.9 \%)$ of the flora of the two areas are considered weeds (Matthei 1995). 
A total of 115 species were identified in the MDT area, 112 of which were classified to species; 66 (57.4\%) are native species, 32 of them also endemic, while $46(40.0 \%)$ are nonnative species. The three other species were not classified by origin since they were identified only to genus, represented by native and non-native species in the area (Tab. S1 in supplementary material). About a third of the species in the MDT area (34.8\%) were weeds (mainly non-native, five of them native) and were found mainly in $C$ habitats $(66 \%$ of the species found in C habitats vs. $20.9 \%$ of species in $\mathrm{UC}$ habitats). A total of 119 species were found in the MM area, $40(33.6 \%)$ were native species (17 endemics to the Chilean Mediterranean climate flora), and 79 (66.4\%) were non-native species. More than half the surveyed species in this area were weeds (57.1\%; mainly non-native, five native), predominating in both habitats $(83.3 \%$ of the species in $C$ habitats and $56 \%$ in UC habitats).

Seven species $(6.0 \%)$ in the MDT area are considered threatened; these are three cactus species (the 'jalajala', Cumulopuntia sphaerica, the 'copao', Eulychnia acida and the 'quisco coquimbano', Trichocereus coquimbanus (Cactaceae)), two other dicotyledonous species (the 'carbonillo', Cordia decandra (Boraginaceae) and the 'palo santo' Porlieria chilensis (Zygophyllaceae)), and two pterydophytes (the 'palito negro', Adiantum chilense and the 'doradilla', Cheilanthes mollis (Pteridaceae)). Only one species in the MM area is considered threatened, the pteridophyte $A$. chilense.

Non-native annual and biannual herbaceous species were most frequent (in terms of number of quadrants with presence) in $C$ habitats in both areas (Tab. 1). In order of importance the families were Poaceae (unidentified grasses), Asteraceae (the 'hierba cana', Senecio vulgaris), Convolvulaceae (the 'correhuela', Convolvulus arvensis), Fumariaceae (the 'hierba de la culebra', Fumaria agraria) and Brassicaceae (the 'mostacilla', Hirschfeldia incana). All are considered weed species that damage crops (Matthei 1995). These species have a wide distribution range in Chile, capable of adapting to different conditions; $S$. vulgaris, $C$. arvensis and F. agraria are considered invasive species in the country (Fuentes et al. 2014). The most frequent were half introduced and half native species, including a threatened cactus species (C. sphaerica) in UC habitats in the MDT area. Introduced herbaceous and woody species were the most frequent in UC habitats in the MM area (Tab. 1). The 'boldo', Peumus boldus Molina (Lauraceae), a tree common to sclerophyllous forests, was the only native species among the ten most common species in UC transects in the MM area.

\section{Species richness}

To assess the difference in native species richness, the GLMM without interaction was selected due to its lowest AIC (2745); the residuals were visually adequate (Fig. S2 in supplementary material). Native species richness was higher in the UC habitats (mean $=1.13 \pm 0.04$ ) than in the $C$ habitats (mean $=0.02 \pm 0.002$ ) (estimate $=3.51$, Std. Error $=0.21, z=16.93, \mathrm{P}<0.0001)$, and higher in the MDT area (mean $=0.91 \pm 0.04)$ than in the MM area (mean $=0.11 \pm 0.01$ ) (estimate $=-1.94$, Std. Error $=0.62, z=-3.14, P<0.002)$. Within the UC habitats, native species richness was higher in the MDT area (mean $=1.51 \pm 0.05)$ than in the MM area $($ mean $=0.63 \pm 0.05)($ estimate $=-1.43$, Std. Error $=0.65$, $\mathrm{z}=-2.22, \mathrm{P}=0.027$ ) (Fig. 2).

To assess the difference in the non-native species richness, the GLMM, including the Habitat-Area interaction, was selected based on its lowest AIC (7030) and visually adequate residuals (Fig. S3 in supplementary material). Neither fixed effect was significant, but the Habitat*Area interaction was significant (estimate $=2.25$, Std. Error $=$ $0.29, \mathrm{z}=7.75, \mathrm{P}<0.0001)$. In the UC habitat, non-native species richness was higher in the MM area than in the MDT

Table 1. Biogeographic origin, weed status (yes or no), life-form, and frequency (i.e., percentage of quadrants with presence) of the most frequent plant species, according to area (MDT: Mediterranean-to-desert transition area; MM: mesic Mediterranean area) and intra-farm habitat (C: cultivated; UC: uncultivated).

\begin{tabular}{|c|c|c|c|c|c|c|}
\hline Area & Habitat & Species & Origin & Weed & Life-form & Frequency (\%) \\
\hline \multirow{8}{*}{ MDT } & \multirow{4}{*}{ C } & Poaceae 1 & unknown & unknown & herbaceous & 16 \\
\hline & & Hirschfeldia incana (L.) Lagr.-Foss. & non-native & yes & herbaceous & 12.4 \\
\hline & & Euphorbia serpens Kunth & non-native & yes & herbaceous & 11.2 \\
\hline & & Helminthotheca echioides (L.) Holub & non-native & yes & herbaceous & 10 \\
\hline & \multirow{4}{*}{$\mathrm{UC}$} & Poaceae 1 & unknown & unknown & herbaceous & 32.4 \\
\hline & & Erodium cicutarium (L.) L’Hér. ex Aiton & non-native & yes & herbaceous & 29.6 \\
\hline & & Gutierrezia resinosa (Hook. \& Arn.) S.F. Blake & endemic & no & shrub & 18.0 \\
\hline & & Cumulopuntia sphaerica (C.F. Först.) E.F. Anderson & native & no & succulent & 13.9 \\
\hline \multirow{8}{*}{ MM } & \multirow{4}{*}{ C } & Senecio vulgaris L. & non-native & yes & herbaceous & 7.5 \\
\hline & & Convolvulus arvensis L. & non-native & yes & herbaceous & 7.4 \\
\hline & & Fumaria agraria Lag. & native & yes & herbaceous & 6.9 \\
\hline & & Lolium multiflorum Lam. & non-native & yes & herbaceous & 3.6 \\
\hline & \multirow{4}{*}{$\mathrm{UC}$} & Rubus ulmifolius Schott. & non-native & yes & shrub & 12.9 \\
\hline & & Eucalyptus globulus Labill & non-native & no & tree & 11.4 \\
\hline & & Ulmus americana L. & non-native & no & tree & 10.7 \\
\hline & & Poa annua L. & non-native & yes & herbaceous & 9.8 \\
\hline
\end{tabular}



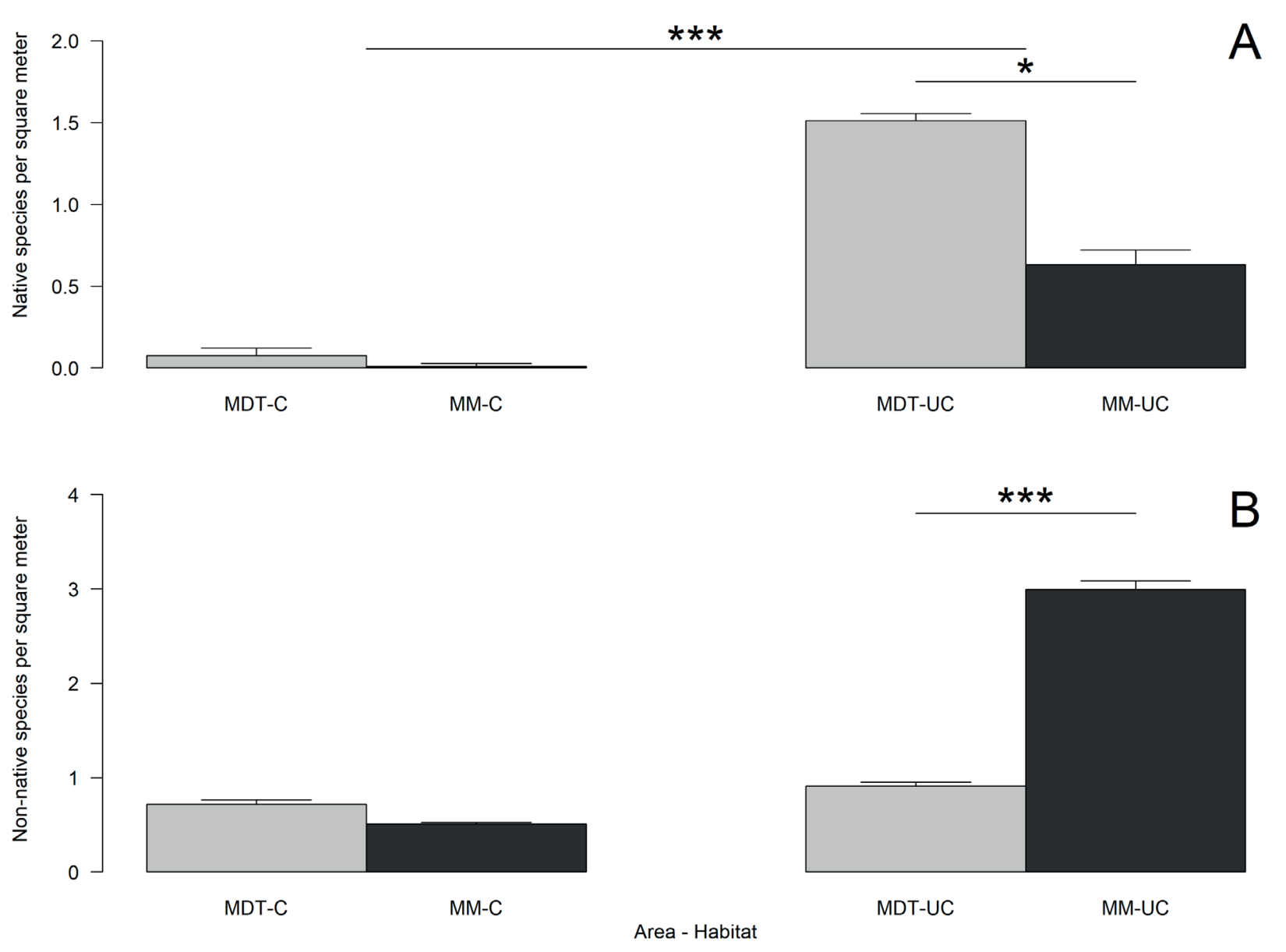

Figure 2. number of species (mean + standard error) per square meter. A) for native species between Mediterranean-to-desert transition area (MDT) and mesic Mediterranean area (MM), within cultivated (C) and uncultivated (UC) habitats; B) for non-native species between MDT and MM areas, within C and UC habitats. Three asterisks mean significance below 0.0001, and one asterisk means significance below 0.05 .

area (estimate $=1.42$, Std. Error $=0.39, \mathrm{z}=3.63, \mathrm{P}<0.001$ ), whereas the difference was not significant in the $C$ habitat (estimate $=-0.75$, Std. Error $=0.50, z=-1.49, P=0.14$ ).

Finally, the Pearson correlation coefficient between the numbers of native and non-native species quadrants was $0.152(\mathrm{P}<0.0001)$ for all data, and $0.07(\mathrm{P}=0.035)$ and 0.32 $(\mathrm{P}<0.001)$ for MDT and MM areas, respectively (Fig. 3 ).

\section{Discussion}

Our study showed that there were more native species in uncultivated habitats, and in uncultivated habitats in the Mediterranean-to-desert transition area than in comparable habitats in the mesic Mediterranean area. Species richness was generally low in both areas and habitat types, with most species considered as weeds (around $90 \%$ non-native) in the prospected conventional fruit farms in central Chile compared to other Mediterranean-climate- type areas (e.g., Alpert et al. 2000).

Native flora is poorly represented in these agroecosystems under agricultural activity. A similarity analysis of the flora on the farms and characteristic native species of a reference ecosystem (according to Luebert \& Pliscoff 2006) found less than $10 \%$ of species shared in the MM area (Arcos 2015). Non-native weed plants (i.e., crop contaminants) predominate in $C$ habitats, but also predominate in UC habitats in the $\mathrm{MM}$ area. Our results on average native species richness (0.02 and 1.13 species $/ \mathrm{m}^{2}$ in $C$ and UC habitats, respectively) are similar to other surveys in Mediterranean climate areas of Chile within sites planted with or invaded by Eucalyptus globulus (Becerra et al. 2018). This seems to be one more indication that the native vegetation in the central valley of the Mediterranean areas of Chile has been replaced (Becerra 2016).

We found richness in both native and non-native species in cultivated habitats to be low, as expected. This may be a result of the application of broad-spectrum herbicides used in these farms. Native species richness in uncultivated habitats was higher in the Mediterranean-to-desert-area than the mesic Mediterranean area. Conversely, more non-native species were found in UC habitats in mesic Mediterranean area, which has a wetter climate. One possible explanation is the difference in annual precipitation between these 

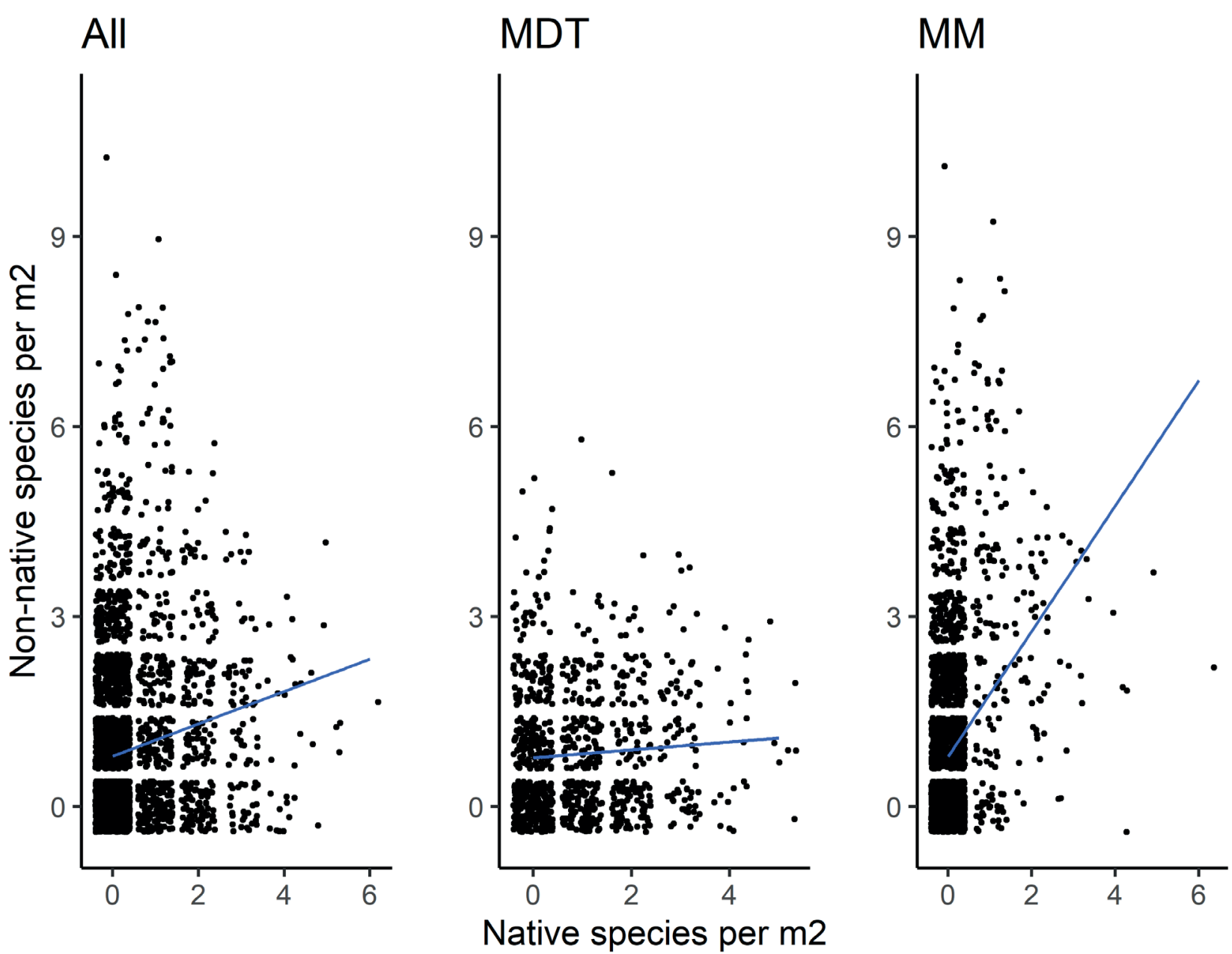

Figure 3. Scatter plots of correlation for native and non-native species according to areas (All data, MDT: Mediterranean-to desert transition area, and MM: mesic Mediterranean area).

areas. Annual precipitation has been identified as the most significant factor favoring non-native plant richness in other Mediterranean ecosystems in Europe and also in central Chile (Carboni et al. 2010; Martín-Forés et al. 2015). Water stress makes habitats less vulnerable to invasive non-native plant species (Alpert et al. 2000). Our results, in concordance with those of Martín-Forés et al. (2015), suggest that wetter Mediterranean-climate areas in Chile are more prone to the establishment of non-native species.

The numbers of native and non-native plant species were significantly positively correlated. This result suggests that competition is not an important factor in the establishment of non-native species (Martín-Forés et al. 2015), and non-native species richness might be responding to environmental factors (Gilbert \& Lechowicz 2005), probably annual rainfall. Congruently, the correlation was stronger in MM area compared with MDT area, where there is more water availability.

In our study we only compared between two areas. Therefore, future studies should confirm if the vulnerability to invasion of weeds from crops is affected by rainfall, contrasting more sites or experimentally. This is particularly important in
Chile because most Chilean fruit farms are located in the part of the country with the highest levels of plant species richness and endemism, but also where flora is most threatened (Muñoz \& Vianna 2012). Protected areas constitute less than $4 \%$ of the surface area in the Chilean regions with Mediterranean bioclimate compared to half of the area in Chilean Patagonia (CONAF 2017). Therefore it is recognized that efforts must go beyond protected areas for biological conservation to be effective (Simonetti et al. 2002). Farms in Chile are more extensive than in other agroecosystems such as Europe; a significant part of them may not be cultivated and could contribute to biological conservation. The most common non-native species in cultivated habitats are invasive species in Chile with high invasive potential (Fuentes et al. 2014). If annual rainfall is influencing the degree to which non-native species from adjacent crop plots can successfully establish in adjacent uncultivated areas, some agroecosystems would be more prone to invasion and consequently deserve more attention in terms of conservation.

Knowledge about the biodiversity on farms is also important for people involved in fruit production. Much of Chilean agriculture, in particular fruit production, is for 
export (Muñoz et al. 2016). Concern has recently emerged among consumers about biodiversity in agroecosystems. As a result, the agricultural export sector must comply with the standards and requirements to reach target markets. However, producers generally know little about the biodiversity on their farms (Muñoz et al. 2016). In contrast, biodiversity in agroecosystems in developed countries has been well studied because of support for agro-environmental and green policies (Aviron et al. 2011; German Federal Environmental Agency 2014). This is not the case for developing countries, many of which are important reservoirs of plant diversity. Consequently, farmers in developing countries face increasing requirements relating to these issues in the context of more demanding markets. From the producers' perspective this represents more demands, but we consider that it is good news for biological conservation. Nonetheless, according to our results cultivated plots under conventional management are not suitable habitats for native species and are not habitats for practically any plant. The majority of the quadrants surveyed in cultivated habitats had no plants $(61.4 \%$ of quadrants in $C$ habitats and $4.9 \%$ in UC habitats) because of herbicide applications. Therefore, restoration with native species or any effort for conservation should be undertaken in uncultivated areas within farms.

In this study we found low and not homogeneously distributed species richness in both areas and habitat types in fruit farms. There were more native species in uncultivated habitats in the Mediterranean-to-desert transition area than in the mesic Mediterranean area, and the contrary was observed for non-native species. Native and non-native plant species were positively correlated, suggesting that competition is not a relevant factor, and non-native species richness may respond to environmental factors such as annual rainfall. This study is an initial contribution to understanding the underlying patterns of native plant assemblages in agroecosystems in this Mediterranean climate hotspot.

\section{Acknowledgements}

We thank the two anonymous reviewers for their valuable comments which helped improve and clarify this manuscript. We thank Dr. Horacio Gillabert for his contribution in the preliminary analyses. Funding: This research was supported by the Innovation Fund for Competitiveness (FIC) for the O’Higgins Region under Grant VCE40000016; and by the Innovation Fund for Competitiveness (FIC) for the Coquimbo Region under Grant BIP 30404141-0.

\section{References}

Alpert P, Bone E, Holzapfel C. 2000. Invasiveness, invasibility and the role of environmental stress in the spread of non-native plants. Perspectives in Plant Ecology, Evolution and Systematics 3: 52-66.
Arcos N. 2015. Evaluación de la variación intra-predial de la flora vascular y su aporte en conservación por predios frutícolas de la Región de O’Higgins, Chile. BSc Thesis, Pontificia Universidad Católica de Chile, Santiago.

Armengot L, Sanz FX, Fischer C, et al. 2012. The $\beta$-diversity of arable weed communities on organic and conventional cereal farms in two contrasting regions. Applied Vegetation Science 15: 571-579.

Arroyo MTK. 1999. Criterios e indicadores para la conservación de la biota de los ecosistemas mediterráneos. Revista Chilena de Historia Natural 72: 473-474.

Aviron S, Herzog F, Klaus I, Schüpbach B, Jeanneret P. 2011. Effects of wildflower strip quality, quantity, and connectivity on butterfly diversity in a swiss arable landscape. Restoration Ecology 19: 500-508.

Barbizan Sühs R, Hettwer Giehl EL, Peroni N. 2018. Interaction of land management and araucaria trees in the maintenance of landscape diversity in the highlands of southern Brazil. PLOS ONE 13: e0206805. doi: 10.1371/journal.pone.0206805

Batjes NH. 2005. SOTER-based soil parameter estimates (SOTWIS) for Latin America and the Caribbean (ver. 1.0). Report 2005/02, ISRIC - World Soil Information, Wageningen. https://library.wur.nl/ WebQuery/wurpubs/fulltext/297830. 1 Nov. 2017.

Baudron F, Giller KE. 2014. Agriculture and nature: Trouble and strife? Biological Conservation 170: 232-245.

Becerra PI. 2016. Relationship between climate and geographical variation of local woody species richness within the Mediterranean type region of Chile. Revista Chilena de Historia Natural 89: 1-11.

Becerra PI, Catford JA, Luce-McLeod M, et al. 2018. Inhibitory effects of Eucalyptus globulus on understorey plant growth and species richness are greater in non-native regions. Global Ecology and Biogeography 27: 68-76.

Boutin C, Baril A, Martin PA. 2008. Plant diversity in crop fields and woody hedgerows of organic and conventional farms in contrasting landscapes. Agriculture, Ecosystems and Environment 123: 185-193.

Boutin C, Jobin B. 1998. Intensity of agricultural practices and effects on adjacent habitats. Ecological Applications 8: 544-557.

Bradley BA, Blumenthal DM, Wilcove DS, Ziska LH. 2010. Predicting plant invasions in an era of global change. Trends in Ecology \& Evolution 25: 310-318.

Carboni M, Thuiller W, Izzi F, Acosta A. 2010. Disentangling the relative effects of environmental versus human factors on the abundance of native and alien plant species in Mediterranean sandy shores. Diversity and Distributions 16: 537-546.

Chappell MJ, LaValle LA. 2011. Food security and biodiversity: can we have both? An agroecological analysis. Agriculture and Human Values 28: 3-26.

Chen C, Huang D, Wang Q, Wu J, Wang K. 2016. Invasions by alien plant species of the agro-pastoral ecotone in northern China: Species-specific and environmental determinants. Journal for Nature Conservation 34: 133-144.

Chytrý M, Jarosik V, Pysek P, et al. 2008. Separating habitat invasibility by alien plants from the actual level of invasion. Ecology 89: 1541-1553.

Clotet M, Basnou C, Bagaria G, Pino J. 2016. Contrasting historical and current land-use correlation with diverse components of current alien plant invasions in Mediterranean habitats. Biological Invasions 18: 2897-2909.

CONAF. 2017. Parques Nacionales. http://www.conaf.cl/parquesnacionales/. 1 Nov. 2017.

Cowling RM, Rundel PW, Lamont B B, Arroyo MK, Arianoutsou M. 1996. Plant diversity in mediterranean-climate regions. Trends in Ecology and Evolution 11: 362-366.

Dirección General de Aguas. 2017. Información oficial hidrometeorológica y de calidad de aguas en línea. https://snia.mop.gob.cl/BNAConsultas/ reportes. 21 Apr. 2017.

FAO. 1988. FAO/UNESCO soil map of the world, Revised Legend (with corrections and updates). FAO World Soil Resources Report 60, ISRIC, Wageningen. https://www.isric.org/sites/default/files/isric_ report_1988_01.pdf.

Fuentes N, Sánchez A, Pauchard A, Urrutia J, Cavieres L, Marticorena A. 2014. Plantas invasoras del centro-sur de Chile: una guía de campo. Concepción, Chile, Laboratorio de Invasiones Biológicas. 
Gassó N, Pino J, Font X, Vilá M. 2012. Regional context affects native and alien plant species richness across habitat types. Applied Vegetation Science 15: 4-13.

German Federal Environmental Agency. 2014. Ecological Focus Areas Crucial for biodiversity in the agricultural landscape! Dessau-roßlau, Umweltbundesamt. https://www.umweltbundesamt.de/sites/default/ files/medien/376/publikationen/ecological_focus_areas_-_crucial_ for_biodiversity_in_the_agricultural_landscape_klu.pdf.

Gilbert B, Lechowicz MJ. 2005. Invasibility and abiotic gradients: The positive correlation between mative and exotic plant diversity. Ecology 86: 1848-1855.

INE. 2007. VII Censo nacional agropecuario y forestal. http://www. censoagropecuario.cl. 12 May 2017.

Instituto de Botánica Darwinion. 2017. Catálogo de las plantas vasculares. http://www.darwin.edu.ar/proyectos/floraargentina/fa.htm. 13 May 2017.

Luebert F, Pliscoff P. 2006. Sinopsis bioclimática y vegetacional de Chile. Santiago de Chile, Editorial Universitaria.

Marticorena C. 1990. Contribución a la estadística de la flora vascular de Chile. Gayana Botanica 47: 85-113.

Martín-Forés I, Sánchez-Jardón L, Acosta-Gallo BA, et al. 2015. From Spain to Chile: environmental filters and success of herbaceous species in Mediterranean-climate regions. Biological Invasions 17: 1425-1438.

Matthei O. 1995. Manual de las malezas que crecen en Chile. Santiago, Alfabeta Impresores.

Moreira-Muñoz A. 2011. Islands on the continent: conservation biogeography in changing ecosystems. In: Moreira-Muñoz A. (ed.) Plant geography of Chile. Dordrecht, Springer. p. 181-194.

Muñoz AE, Bonacic C, Arellano E. 2016. ¿Por qué es importante conservar la biodiversidad en los predios agrícolas de Chile central? In: Muñoz, AE, Bonacic C, Arellano E. (eds.) Manual de conservación de biodiversidad en predios agrícolas de Chile central. Macul, Pontificia Universidad Católica de Chile. p. 6-8.

Muñoz AE, Vianna J. 2012. El desafío de la biodiversidad en la agricultura. Agronomía y Forestal 46: 8-13.
Myers N, Mittermeier RA, Mittermeier CG, Fonseca GAB, Kent J. 2000. Biodiversity hotspots for conservation priorities. Nature 403: 853-858.

Phalan B, Onial M, Balmford A, Green RE. 2011. Reconciling food production and biodiversity conservation: land sharing and land sparing compared. Science 333: 1289-1291.

Pozo A, Ovalle C, Casado MA, Acosta B, de Miguel JM. 2006. Effects of grazing intensity in grasslands of the Espinal of central Chile. Journal of Vegetation Science 17: 791-798.

R Development Core Team. 2019. R: A Language and Environment for Statistical Computing. R Foundation for Statistical Computing, Vienna, Austria. https://www.R-project.org/. 1 Nov. 2017.

Ramírez N. 2015. Caracterización y análisis de la flora vascular en predios frutícolas de exportación de la Región del Libertador General Bernardo OHiggins. BSc Thesis. Pontificia Universidad Católica de Chile, Santiago.

Rodriguez R, Marticorena C, Alarcón D, et al. 2018. Catálogo de las plantas vasculares de Chile. Gayana Botanica 75: 1-430.

Simonetti J, Grez A, Bustamante R. 2002. El valor de la matriz en la conservación ambiental. Ambiente y Desarrollo 18: 116-118.

Skaug HJ, Fournier DA, Nielsen A, Magnusson A, Bolker BM. 2016. Generalized Linear Mixed Models using 'AD Model Builder'. R Packag version 0833. https://rdrr.io/rforge/glmmADMB/. 1 Nov. 2017.

Underwood EC, Viers JH, Klausmeyer KR, Cox RL, Shaw MR. 2009. Threats and biodiversity in the mediterranean biome. Diversity and Distributions 15: 188-197.

Waldhardt R, Simmering D, Albrecht H. 2003. Floristic diversity at the habitat scale in agricultural landscapes of Central Europe Summary, conclusions and perspectives. Agriculture, Ecosystems and Environment 98: 79-85.

Warnes GR, Bolker B, Bonebakker L, et al. 2020. gplots: various R programming tools for plotting data. $\mathrm{R}$ package version 3.0.1.2. https://rdrr.io/cran/gplots/. 1 Nov. 2017.

Wickham H. 2016. ggplot2: Elegant Graphics for Data Analysis. New York, Springer.

Zuur AF, Ieno EN, Walker NJ, Saveliev AA, Smith GM. 2009. Mixed Effects Models and Extensions in Ecology with R. New York, Springer. 